\title{
Acute and chronic peripheral nerve stimulation: Surgical preparation and electrode design*
}

\author{
RICHARD A. GALOSY $\dagger$ and JAMES L. HOWARD \\ Department of Psychiatry \\ and Biological Sciences Research Center of the \\ Child Devc 'opment Institute, University of North Carolina \\ Chapel Hill, North Carolina 27514
}

An electrode for peripheral nerve stimulation and surgical procedures for implantation are described. Results indicating its effectiveness are provided with discussion of durability and applicability.

The purpose of this paper is to describe the design of a stimulating electrode for peripheral nerves and surgical procedures for its implantation. The electrode and procedures have been used in two studies. Galosy, Howard, Gaebelein, and Obrist (1973) placed the electrode on the right cervical vagus and the sympathetic trunk just below the right stellate ganglion in cats; the effects of various neuromuscular blocking drugs on the cardiovascular response to nerve stimulation were assessed. In the second study ${ }^{1}$, the ansa subclavia of dogs in both the acute and chronic state was stimulated for the purpose of assessing the effect of changes in sympathetic activity on cardiovascular hemodynanics.

\section{METHOD \\ Surgical}

The surgical techniques for both acute and chronic experiments were essentially the same, with additional precautions taken for chronic implantations. Therefore, the more detailed sterile surgical technique will be described. All surgical preparations were conducted in the surgical suites of the Laboratory of Animal Medicine of the University of North Carolina.

The Ss were anesthetized with Suritol (sodium thiamylal, Parke-Davis and Co., Detroit, Michigan) administered IV (sodium pentobarbital, MedTech Inc., St. Joseph, Missouri, was used for acute experiments) and respirated with a mixture of metathane and $\mathrm{O}^{2}$ via a Bird respirator. An IV drip of Ringer lactate solution was provided throughout the duration of surgery. Prior to surgery, Ss were treated with $1 \mathrm{mg}$ atropine IV (Burroughs-Wellcome and Co., Tuchahoe, New York).

Entry to the thoracic cavity was made through a 3- to 5-in. incision above the first or second intercostal space. As the thoracotomy was performed, care was taken to ligate any large vessels encountered prior to their being severed. Once the thorax was entered, the ribs were spread with chest retractors and the left lobe of the lung carefully held from view by a lung retractor.

\footnotetext{
*Reprint requests should be addressed to Richard A. Galosy, Pauline and Adolph Weinberger Laboratory for Cardiopulmonary Research, Departme $t$ of Internal Medicine, University of Texas Health Services Ces er, Dallas, Texas 75235. This research was supported in part i Grant MH-07995 from NIMH and Institutional Grant HD-031 10 NICHD, United States Public Health Service.

TThis research was conducted whi the first author was a predoctoral fellow in the Department of Psychology, Training Grant NIMH MH-12383.
}

This preparation provided excellent exposure of and easy access to the stellate and caudal cervical ganglions and their respective branches. After blunt dissection of the ansa subclavia, the stimulating electrode was placed around the nerve above the left subclavian artery. At this time, the electrode was closed around the nerve and lightly secured to the left subclavian artery by 0 silk. Additional stability was provided by sutering the pleural lining around the electrode with 4-0 gut. This proved to be an excellent method of holding the electrode in place until sufficient fibrotic growth occurred to completely lock the electrode into place.

Before reconstructing the chest, the electrode was activated to verify its placement and the lungs inflated by increasing inspiration volume on the respirator to reinstate any collapsed areas. The electrode lead then exited through the interspace where it was secured to the rib with 0 silk, after which a 14-french Rob-Nel chest tube (Sherwood Medical Industries, SH-114, St. Louis, Missouri) which could be opened and closed with a three-way stopcock was inserted into the ventral portion of the thorax through the fourth interspace for purposes of air and fluid evacuation. The chest tube was held in place by a purse string stitch in the skin. The ribs were then pulled together with a towel clamp and permanently held by several stainless steel sutures ( 00 surgical steel). Muscle layers were closed with 2-0 chromic gut, the first layer with a continuous chain stitch and the others with an interrupted mattress stitch. Prior to closing the skin, the electrode lead was passed subcutaneously and exited through a small incision on the S's back. All skin incisions were treated with Neosporine and then closed with Vetafil using an interrupted mattress stitch.

Postoperative treatment consisted of daily injections of
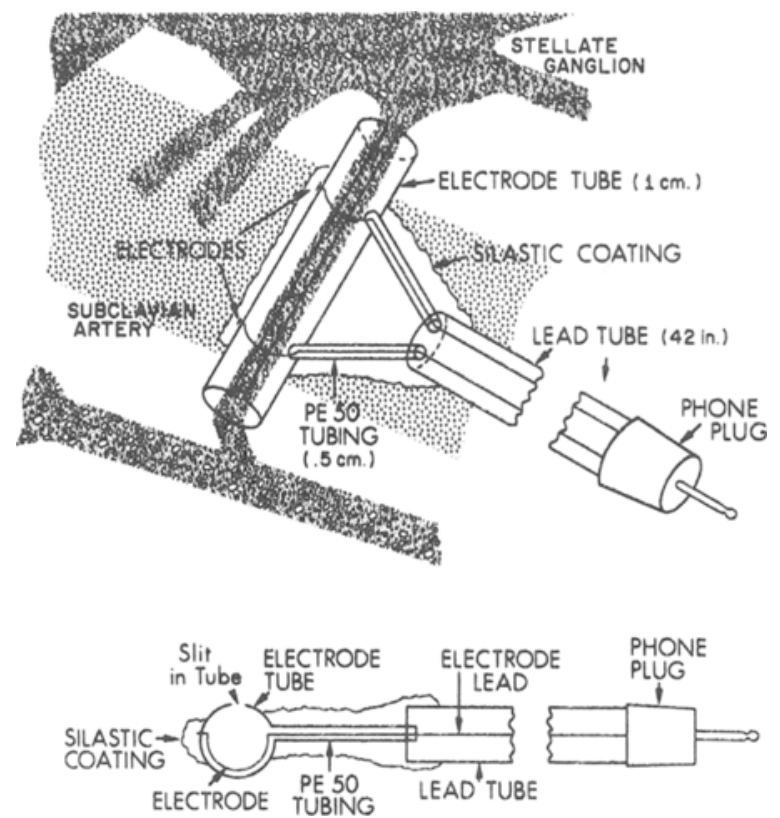

Fig. 1. Schematic representation of the stimulating electrode from an oblique, on the nerve bundle, and side view. 


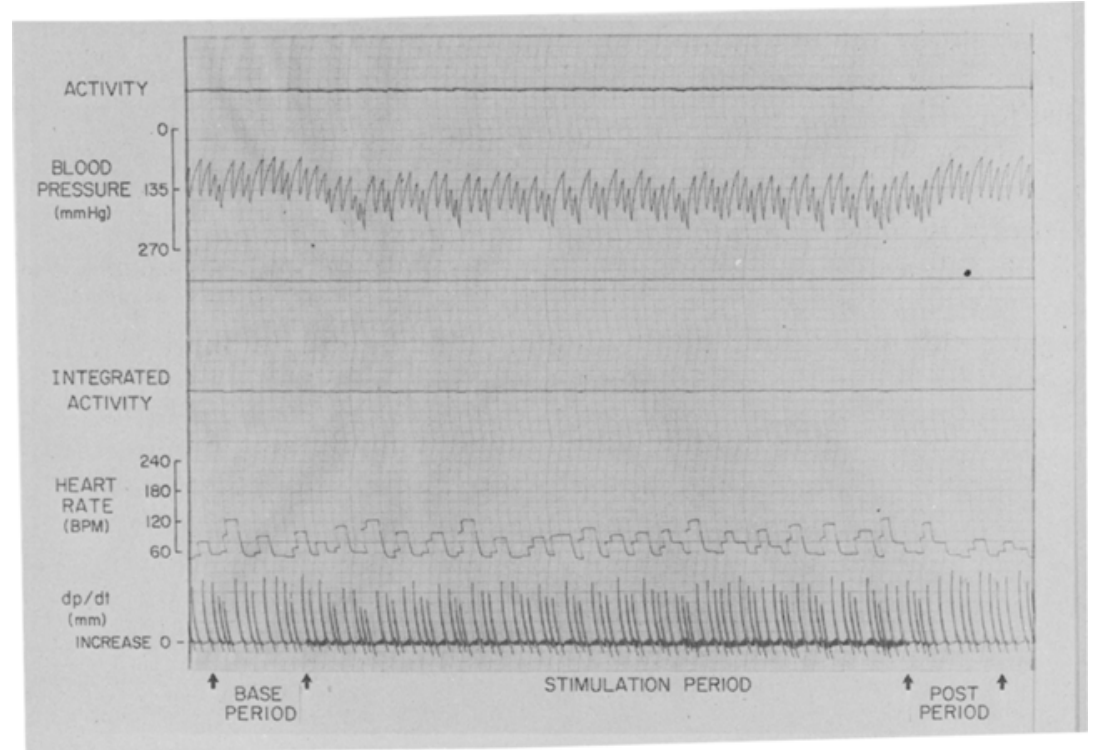

Fig. 2. Shows the changes in blood pressure (BP), gross body movements (activity and integrated activity), heart rate (HR), and maximum rate of change in aortic BP (dp/dt) to stimulation of the left ansa subclavia in the chronic unanesthetized dog.

standard antibiotics and chest evacuation for 3-5 days. Wound dressings were of $4 \times 4$ in. gauze pads treated with Furacin cream (Eaton Veterinary Laboratories, Norwich, New York) held in place by elastic bandages wrapped around the S's thorax. Each S was placed in a special jacket (Alice King Chatham, Medical Arts, Los Angeles, California) that protected the leads and wounds.

\section{Electrode}

The stimulating electrode (see Fig. 1) consisted of a $1-\mathrm{cm}$ length of either 8-or 5-french Bardic feeding tube, medical grade (Nos. 1730 and 1733), which could be slit longitudinally for placement around the nerve. The lead wires were multistranded silver wire coated with Teflon (Medwire, Mount Vernon, New York). Two bared strands of wire (.008 bare) entered one side of the tube, looped along the inside, and exited from the opposite side, where they were cemented into place by Zipbond (Tescomp Corp., Minneapolis, Minnesota). The coated leads from the electrode tube were each covered by a .5-cm length of PE 50 tubing (Intramedic, No.7411, Clay Adams, Parsipany, New York) that angled together and fitted into either an 8-or 12-french Bardic feeding tube (lead tube). Zipbond cement was used to anchor the PE 50 tubing to both the electrode and lead tube. The remainder of the electrode leads passed inside the lead tube, at the end of which both leads and tube were connected to a male-type phone plug that could be attached to the stimulator leads. Additional strength of the bond between the electrode and lead tube was provided by Zipbonding a $1.5-\mathrm{cm}$ length of 14-french tubing to both the lead and electrode tubes. Silastic (Medical Adhesive silicone, Type A891, Dow Corning Corp., Midland, Michigan) was used to encase the entire electrode proper, and it was allowed to dry for at least $24 \mathrm{~h}$. Stimulation parameters have been $6-10 \mathrm{~Hz}, 5 \mathrm{msec}$ duration, $1-5 \mathrm{~mA} \mathrm{ac}$ current from a Grass Model SD9 stimulator.

\section{RESULTS AND DISCUSSION}

In general, the electrode design and surgical procedures resulted in consistent and easily controlled stimulation of whole nerve bundles in both the acute and chronic preparation. Figure 2 shows the response to

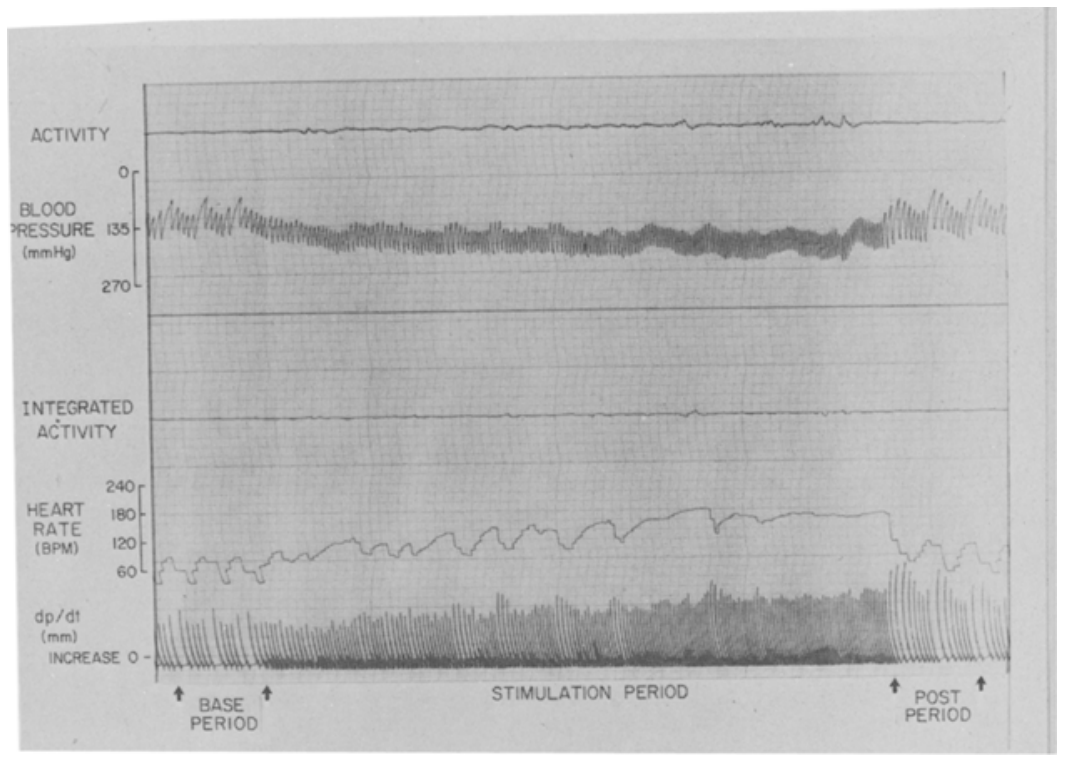

Fig. 3. Shows the changes in blood pressure (BP), gross body movements (activity and integrated activity), heart rate (HR), and the maximum rate of change in aortic BP $(\mathrm{dp} / \mathrm{dt})$ to stimulation of the left ansa subclavia in the chronic anesthetized dog. 
stimulation in the chronic dog preparation with the $S$ unanesthetized. Figure 3 indicates the responseof the same dog while anesthetized.

These electrodes can remain functional for at least 2 months as long as no unnecessary strain is placed on the electrode lead for about 10 days. Although to date the electrode has only been used in dogs and cats, it could be modified for application in any $S$ on any nerve bundle which would allow for at least .5 -cm separation of the electrodes by simply constructing the electrode tube of different-sized tubing.

\section{REFERENCE}

Galosy, R. A., Howard, J. L., Gaebelein, C. J., \& Obrist, P. A Neuromuscular blocking drugs and the heart rate response to direct pre-ganglionic stimulation of the sympathetics and parasympathetics in the cat. Psychophysiology, 1973, 10 196. (Abstract)

\section{NOTE}

1. Galosy, R. A. Sympathetic stimulation and cardiovascula hemodynamics in dogs. Doctoral dissertation in preparation.

(Received for publication October 4, 1973; revision received November $21,1973$. ) 